\title{
Optimal operation management of Grid-Connected microgrids under uncertainty
}

\author{
Surender Reddy Salkuti \\ Department of Railroad and Electrical Engineering, Woosong University, Republic of Korea
}

\begin{tabular}{l} 
Article Info \\
\hline Article history: \\
Received Apr 7, 2019 \\
Revised Jun 30, 2019 \\
Accepted Jul 29, 2019 \\
\hline
\end{tabular}

\section{Keywords:}

Battery energy storage

Demand response

Electric vehicles

Microgrid

Renewable energy sources

\begin{abstract}
This paper proposes a new optimal operation of Microgrids (MGs) in a distribution system with wind energy generators (WEGs), solar photovoltaic (PV) energy systems, battery energy storage (BES) systems, electric vehicles (EVs) and demand response (DR). To reduce the fluctuations of wind, solar PV powers and load demands, the BES systems and DR are utilized in the proposed hybrid system. The detailed modeling of WEGs, solar PV units, load demands, BES systems and EVs has been presented in this paper. The objective considered here is the minimization of total operating cost of microgrid, and it is formulated by considering the cost of power exchange between the main power grid and microgrid, cost of wind and solar PV energy systems, cost of BES systems, EVs and the cost due to the DR in the system. Simulations are performed on a test microgrid, and they are implemented using GAMS software. Various case studies are performed with and without considering the proposed hybrid system.
\end{abstract}

Copyright $@ 2019$ Institute of Advanced Engineering and Science. All rights reserved.

\section{Corresponding Author:}

Surender Reddy Salkuti, Department of Railroad and Electrical Engineering, 17-2, Woosong University, Jayang-dong, Dong-gu, Daejeon-34606, Republic of Korea. Email: surender@wsu.ac.kr

\section{INTRODUCTION}

In recent years, the renewable energy/green energy technologies are growing rapidly and they are set to reach ambitious targets as they have the ability to reduce energy crisis with environmentally friendly manner. Denmark has set a target of $50 \%$ of its power demand from renewables by 2030, whereas Germany has set a target of 35\% and UK has set a target of 30\% of its power demand from renewables by 2020 [1]. Renewable energy sources (RESs) such as wind power and solar photovoltaic (PV) energy are often spatially distributed and inherently intermittent and unpredictable. The power output of RESs depends on the wind speed, solar irradiation, and other climatic factors, which are uncertain and intermittent in nature. Various countries are moving towards the microgrid with RERs and other locally available distributed generation sources to get the benefits of providing power to remote areas with high power quality and reliability. Microgrid (MG) is an active distribution network, which can operate in both island and connected modes. In island mode, MG is disconnected from the main grid, and it supplies their loads with existing distributed generations (DGs). The majority of DGs used in MGs are renewable types, which are connected to the grid by inverters as switch mode power supplies. Microgrids with RESs and electric vehicles (EVs) can reduce the emissions, loss reduction, costs of energy supply, peak shaving, enhances the reliability, voltage profile and improves power quality [2].

The integration of wind, solar PV energy systems, EVs, BES systems and demand response (DR) provides additional energy and storage options to the microgrid. The survey on existing research works on the optimal strategies for the operation of MGs is proposed in [3]. Reference [4] reviews and compares different optimization techniques applied for achieving optimal operation of MGs from diverse perceptions, 
in terms of objective functions, optimization techniques, constraints and computational performances. An operation optimization modeling for a MG considering the distributed generation, environmental factors and DR is proposed in [5]. Reference [6] presents an optimal power balancing model of distributed systems with distributed generation and EVs based on quadratic rotated conic programming. An optimal day-ahead scheduling and control models for MGs under uncertainty is proposed in reference [7]. A mathematical model to compute the optimal operation schedule that embodies DR in MG is presented in [8]. The impact of DR program intensity and BES system size on the operation of networked MGs is analyzed while considering the prevailing uncertainties is proposed in [9]. In [10], the DR program and battery are utilized to tackle the stochastic nature of wind, solar power generation and load demand to utilize an energy management system to manage hourly power of MG and optimally supply the demand. An approach to review the role of renewable energy as an energy producer in unit commitment scheduling problem is proposed in [11].

An optimal robust model for short-term operational scheduling of distribution network in the presence of uncertainties to minimize the cost of network operation is proposed in [12]. Utilization of PV systems for EVs charging for transportation requirements of smart cities is proposed in [13]. An economic dispatch problem of MG, i.e., to minimize the fuel cost of dispatchable DGs by using four different optimization techniques - lambda iteration, lambda logic, direct search method, and particle swarm optimization is proposed in [14]. In [15], energy storage units are considered as an effective option for handling the imbalance of wind power generation. Reference [16] proposes an approach to integrate power to gas technology to the multi-source MG including wind power, electric boiler, micro turbine and gas boiler. In [17], the energy storage systems and DR are introduced to the traditional scheduling model of wind and thermal power with carbon emission trading for reducing the influence of random nature of wind power on system operation. From the above literature review, it can be observed that there is a pressing requirement for an optimal operation of MG considering the RESs, BES systems, EVs and DR [18-20].

The main contribution of this paper is to optimize the total operating cost of microgrid (MG) by considering the power exchange between main power grid and MG, renewable energy sources, battery energy storage system, electric vehicles and demand response. In this paper, an optimal scheduling methodology is presented for the MGs in large distribution systems. Here, the energy storage batteries and EVs are used to improve the operational flexibility of the system and to increase the penetration of RESs. The demand response that is considered in this paper will work as an operating tool for the improvement of reliability and efficiency of MG. The aim of demand response is to encourage the customers to become active partners of MG energy management system.

\section{MODELING OF MICROGRID COMPONENTS}

Modeling of MG components such as WEGs, solar PV units, load demands, BES systems and EVs are presented in this paper. The detailed modeling of wind energy generators, solar PV units and load demands and their uncertainty handling approaches has been presented in references [21-23].

\subsection{Modeling of Battery Energy Storage (BES) System}

Generally, the battery is considered as constant voltage source. BES system is used to smooth out the energy supply by absorbing energy when the power generated by renewables is more than the scheduled power, and dispensing energy when the renewables do not fulfill the load demand. Charge/discharge power limits of battery are expressed as [24-25],

$$
\begin{aligned}
& 0 \leq P_{B, k}^{c h, t} \leq P_{B, k}^{c h, \max } \\
& 0 \leq P_{B, k}^{\text {disch,t }} \leq P_{B, k}^{\text {disch,max }}
\end{aligned}
$$

where $P_{B, k}^{\text {ch,max }}$ and $P_{B, k}^{\text {disch,max }}$ are the maximum charging and discharging rates of battery [26]. The state of charge (SOC) of battery plays a major role in controlling the charging/discharging and in optimal scheduling of battery [27]. The constraints on SOC of storage battery are expressed as,

$$
\begin{aligned}
& S O C_{k}^{\min } \leq S O C_{k}^{t} \leq S O C_{k}^{\max } \\
& S O C_{k}^{t}=\left(\frac{C_{B E S, k}^{t}}{C_{\max }}\right)
\end{aligned}
$$


where $S O C_{k}^{\text {min }}$ and $S O C_{k}^{\text {max }}$ are minimum and maximum BES capacity limits, respectively. The $C_{B E S, k}^{t}$ can be expressed as [28],

$$
C_{B E S, k}^{t}=C_{\text {init }}+\left(P_{B, k}^{c h, t} \eta_{c h}\right)-\left(P_{B, k}^{\text {disch }, t} \eta_{\text {disch }}\right)
$$

where $C_{\text {init }}$ is the initial capacity of battery storage system.

\subsection{Modeling of Electric Vehicles (EVs)}

EVs will play two roles when they plug into a MG. These EVs will appear as loads during the charging, and they also used as storage units to supply energy to the remaining load demands, if the batteries have the sufficient spare energy. The battery of EV acts as a source of stored energy to provide a number of ancillary services to supply primary and secondary control and voltage control. The battery systems of EV are the chemical storage devices, and they are exponential functions over time. The instantaneous charging status of the battery system of EV is expressed as [29],

$$
P_{E V}^{t}=P_{E V}^{\max }\left(1-e^{\alpha t / t_{\max }}\right)+P_{E V}^{0}
$$

where $P_{E V}^{0}$ is the current status of battery system, $P_{E V}^{\max }$ is the maximum power capacity of EV, $t_{\max }$ is the maximum charging time. Similarly, the discharging status of the battery system of EV is expressed as [30],

$$
P_{E V}^{t}=P_{E V}^{0} \cdot e^{\left(\alpha t / t_{\max }\right)}
$$

where $\alpha$ is a constant parameter and it is calculated by considering a fully empty battery system of EV that absorbs $97 \%$ of maximum power capacity, and its value is approximately equal to $\left(t_{\max } / 3\right)$.

\section{PROBLEM FORMULATION}

The proposed structure of MG that has been considered in this paper is depicted in Figure 1. In this paper, the power exchange between main power grid and $\mathrm{MG}$ is considered. The components that are considered in the proposed MG structure are: distributed generators (i.e., WEGs and solar PV units), BES systems, EVs and demand response. The EV aggregator collects the information of charging/discharging strategies of EV batteries in electric vehicles [31]. The EV aggregator participates in the market clearing process to reduce the total operating cost (TOC) of the system by determining the mode of operation of EV and to provide an operational flexibility.

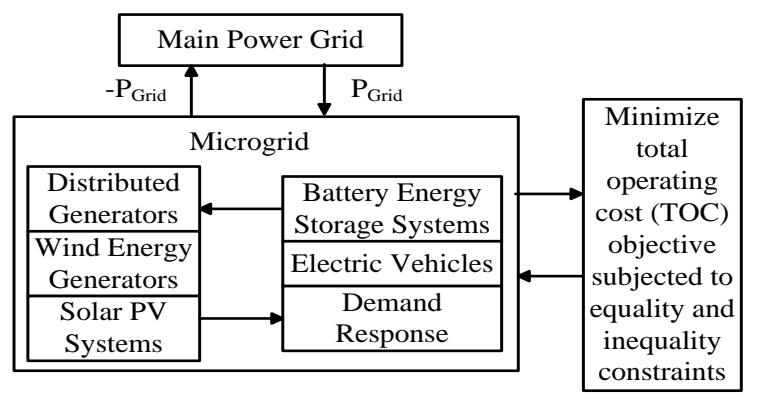

Figure 1. Proposed Structure of Microgrid (MG)

The objective considered in this paper is to minimize the total operating cost (TOC) of the system, which is the sum of cost due to power exchange between main power grid and MG, cost due to power output from WEGs, solar PV units, BES systems, EVs and demand response [32]. Mathematically, it can be expressed as,

Minimize TOC,

$$
T O C=\sum_{t=1}^{T}\left[C_{G r i d}^{t}\left(P_{\text {Grid }}^{t}\right)+\sum_{i=1}^{N_{W}} C_{W}^{t}\left(P_{W, i}^{t}\right)+\sum_{j=1}^{N_{P V}} C_{S}^{t}\left(P_{P V, j}^{t}\right)+\sum_{k=1}^{N_{B}} C_{B}^{t}\left(P_{B, k}^{t}\right)+\sum_{l=1}^{N_{E V}} C_{E V}^{t}\left(P_{E V, l}^{t}\right)+C_{D R}^{t}\left(P_{D R}^{t}\right)\right]
$$


The first component in (8) represents the cost due to power exchanged between main grid and MG, and it can be expressed as [33],

$$
C_{\text {Grid }}^{t}\left(P_{\text {Grid }}^{t}\right)=C_{\text {Grid }}^{t} \cdot P_{\text {Grid }}^{t}
$$

where $P_{\text {Grid }}^{t}$ is the power output from main power grid at hour t. $P_{\text {Grid }}^{t}$ is positive if the main grid transmits power to the MG, and it is negative if the main grid absorbs power from the MG. Second term in (8) represents the direct cost associated with wind power and it is expressed as [34],

$$
C_{W}^{t}\left(P_{W, i}^{t}\right)=C_{W}^{t} \cdot P_{W, i}^{t}
$$

Third term in (8) represents the direct cost for the scheduled solar PV power, and it is expressed as, $C_{S}^{t}\left(P_{P V, j}^{t}\right)=C_{S}^{t} \cdot P_{P V, j}^{t}$

Fourth component in (8) represents the operating cost of BES system, which includes the installation and degradation costs, and it can be expressed as,

$$
C_{B}^{t}\left(P_{B, k}^{t}\right)=C_{B, k}\left(P_{B, k}^{c h, t}+P_{B, k}^{\text {disch }, t}\right)
$$

Fifth component in (8) represents the cost associated with the charge/discharge power of EV, and it can be expressed as,

$$
C_{E V}^{t}\left(P_{E V, l}^{t}\right)=C_{E V}^{t} \cdot P_{E V, l}^{t}
$$

Last component in (8) represents the cost due to incentive based demand response (DR), and it can be expressed as,

$$
C_{D R}^{t}\left(P_{D R}^{t}\right)=C_{D R}^{t} \cdot P_{D R}^{t}
$$

where $P_{D R}^{t}$ is the amount of planned power/load reduction, $C_{D R}^{t}$ is the incentive payment for load reduction. constraints.

The above objective function is solved subjected to the following equality and inequality

\subsection{Power Balance Constraints}

This equality constraint of MG system maintains the balance between power generation/supply and demand. This constraint is expressed as [35],

$$
P_{\text {Grid }}^{t}+\sum_{i=1}^{N_{W}} P_{W, i}^{t}+\sum_{j=1}^{N_{P V}} P_{P V, j}^{t}+\sum_{k=1}^{N_{B}} P_{B, k}^{t}+\sum_{l=1}^{N_{E V}} P_{E V, l}^{t}+\sum_{m=1}^{N_{L}} P_{D R, m}^{t}=P_{L}^{t}+P_{\text {loss }}^{t}
$$

where $t=1,2, \ldots, T . P_{L}^{t}$ is the total system load at hour $\mathrm{t}$.

\subsection{Power Generation Capacity Constraints}

For stable operation of MG, the active power output of each MG component is limited by lower and upper bounds, and they are expressed as [36],

$$
\begin{aligned}
& P_{\text {Grid, } t}^{t, \text { min }} \leq P_{\text {Grid }}^{t} \leq P_{\text {Grid }, t}^{t, \text { max }} \\
& P_{W, i}^{t} \leq P_{W, i}^{\max } \\
& P_{P V, j}^{t} \leq P_{P V, j}^{\max } \\
& P_{D R}^{t} \leq P_{D R, \max }^{t}
\end{aligned}
$$

where $P_{W, i}^{t}$ is the power generated by ith WEG at hour t, $P_{W, i}^{\max }$ is its upper limit, $P_{P V, j}^{t}$ is the power generated by the jth solar PV unit at hour $\mathrm{t}, P_{P V, j}^{\max }$ is its upper limit, and $P_{D R, \max }^{t}$ is the maximum allowed load reduction at hour $t$. 


\subsection{Constraints on BES System}

The state of charge (SOC) balance equation of a BES system is expressed as,

$$
\operatorname{SOC}^{t}=\operatorname{SOC}^{t-1}+I^{t} \Delta t
$$

where $I^{t}$ is the charge (+)/discharge (-) current (in kA). The charge/discharge current limits are expressed as [26],

$$
I^{\min } \leq I^{t} \leq I^{\max }
$$

\subsection{Constraints on Transmission Line Capacity}

As mentioned earlier, the capacity of transmission line that connects between the main power grid and MG can be expressed as,

$$
-P_{L}^{\max } \leq P_{L, t} \leq P_{L}^{\max }
$$

where $P_{L}^{\max }$ is the maximum capacity of transmission line.

\section{RESULTS AND DISCUSSION}

The Microgrid (MG) considered in this paper has the WEGs, solar PV units, battery banks, electric vehicles (EVs), demand response and the power exchange between MG and main power grid. In this system, four wind mills with the capacity of $750 \mathrm{~kW}$ each, four solar PV plants with the capacity of $250 \mathrm{~kW}$ each, two battery units with the capacity of $250 \mathrm{~kW}$ each and two electric vehicle aggregators with the capacity of $200 \mathrm{~kW}$ each are considered. Hourly load demand, wind speed and solar irradiation data for 24 hour period has been presented in Table 1. The optimization problem formulated in this paper has been implemented by using Generalized Algebraic Modeling Systems (GAMS) software and solved by SNOPT solver [36]. All the developed programs were run on a personal computer with Intel Core i7, 3.0GHz and 8GB RAM. In this paper, $v_{c i}, v_{c o}$ and $v_{r}$ are considered as $3 \mathrm{~m} / \mathrm{s}, 25 \mathrm{~m} / \mathrm{s}$ and $10 \mathrm{~m} / \mathrm{s}$, respectively.

Table 1. Load Demand, Wind Speed and Solar Irradiation Data for 24 Hour Period

\begin{tabular}{cccccccc}
\hline 8 & $\begin{array}{c}\text { Load } \\
(\mathrm{kW})\end{array}$ & $\begin{array}{c}\text { Wind speed } \\
(\mathrm{m} / \mathrm{s})\end{array}$ & $\begin{array}{c}\text { Solar irradiation } \\
\left(W / \mathrm{m}^{2}\right)\end{array}$ & Hour & $\begin{array}{c}\text { Load } \\
(\mathrm{kW})\end{array}$ & $\begin{array}{c}\text { Wind speed } \\
(\mathrm{m} / \mathrm{s})\end{array}$ & $\begin{array}{c}\text { Solar irradiation } \\
\left(W / \mathrm{m}^{2}\right)\end{array}$ \\
\hline 1 & 2200 & 5.7 & 0 & 13 & 5300 & 5.9 & 833 \\
2 & 2400 & 6.5 & 0 & 14 & 5200 & 4.9 & 850 \\
3 & 2800 & 7.5 & 0 & 15 & 5000 & 3.5 & 680 \\
4 & 3200 & 6.9 & 0 & 16 & 4600 & 3.4 & 595 \\
5 & 3400 & 8.6 & 93.5 & 17 & 4000 & 2.8 & 255 \\
6 & 3800 & 10.5 & 212.5 & 18 & 3700 & 3.1 & 12.5 \\
7 & 4000 & 13.6 & 255 & 19 & 3400 & 2.3 & 68 \\
8 & 4200 & 10.4 & 467.5 & 20 & 3200 & 2.9 & 42.5 \\
9 & 4600 & 9.1 & 637.5 & 21 & 3000 & 3.5 & 0 \\
10 & 5000 & 9.3 & 680 & 22 & 2800 & 3.8 & 0 \\
11 & 5200 & 7.7 & 816 & 23 & 2600 & 3.8 & 0 \\
12 & 5400 & 7.0 & 850 & 24 & 2400 & 4.8 & \\
\hline
\end{tabular}

In this paper, four different case studies are performed, and they are described next:

a) Case 1: Considering the power output only from main power grid.

b) Case 2: Considering the power output from main power grid and renewable energy sources (RESs).

C) Case 3: Considering the power output from main power grid, RESs, BES systems and electric vehicles (EVs).

D) Case 4: Considering the power output from main power grid, RESs, BES systems, EVs and demand response.

\subsection{Case 1}

In this case, the objective function consists only first term of (8), (i.e., cost due to power output from main power grid. As mentioned earlier, this objective function is solved by using the SNOPT solver of GAMS software, and the obtained results are reported in Table 2. The total operating cost (TOC) obtained in this case is $590158.5 \$$ day, and this cost is due to the power output from main power grid. 


\subsection{Case 2}

In this case, the objective function consists only first three of (8), (i.e., cost due to power exchange from main power grid and MG, and renewable energy sources (i.e., wind farms and solar PV plants)). The forecasted and actual power outputs of WEGs and solar PV units are depicted in Figure 2. Table 2 also presents the optimum objective function values for this case. The optimum cost incurred in this case for the 24 hours scheduling period is $515792.1 \$ /$ day, which is the sum of cost of power exchange between main power grid and MG (i.e., 116604.3\$/day), cost of wind power generation (301567.2\$/day) and the cost of solar PV power generation (97620.6\$/day). The total operating cost (TOC) obtained in this case is $12.6 \%$ less than the cost obtained in Case 1.

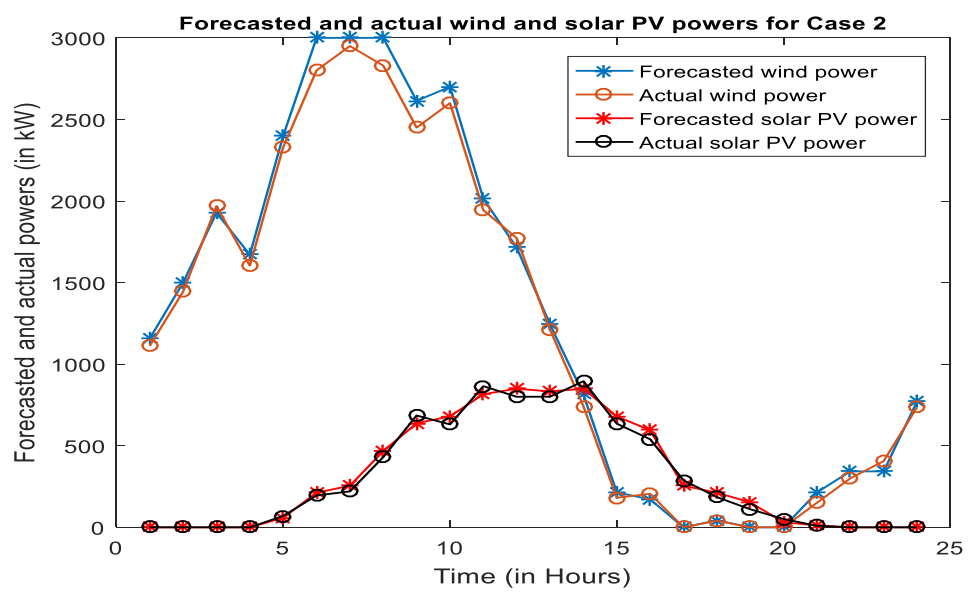

Figure 2. Forecasted and actual wind and solar PV powers for Case 2

Table 2. Optimum Objective Function Values for Cases 1, 2, 3 And 4.

\begin{tabular}{ccccc}
\hline Objective Function Values & Case 1 & Case 2 & Case 3 & Case 4 \\
\hline Cost of power from main power grid (in \$/day) & 590158.5 & 116604.3 & 71512.6 & 45762.5 \\
Cost of wind power generation (in \$/day) & - & 301567.2 & 295391.3 & 284691.8 \\
Cost of solar PV power generation (in \$/day) & - & 97620.6 & 91359.7 & 87368.4 \\
Cost of battery storage and EVs (in \$/day) & - & - & 42128.2 & 39850.5 \\
Cost of demand response (in \$/day) & - & - & - & 36484.2 \\
Total operating cost (in \$/day) & 590158.5 & 515792.1 & 500391.8 & 494157.4 \\
Cost reduction (in \%) & - & 12.6 & 15.2 & 16.3 \\
\hline
\end{tabular}

\subsection{Case 3}

In this case, the objective function consists all the terms of (8) except last term, (i.e., cost due to power output from main power grid and MG, renewable energy sources (i.e., wind farms and solar PV plants) and battery energy storage (BES) system). In this case, to extend the lifetime of BES system, the $S O C_{k}^{\min }$ and $S O C_{k}^{\max }$ of the BES system are set to be $20 \%$ and $80 \%$, respectively. This BES system stores the energy during the off-peak hours by charging the battery until it reaches $S O C_{k}^{\max }$; whereas during the peak hours, it injects the stored energy to loads until it reaches $S O C_{k}^{\mathrm{min}}$.

The TOC obtained in this case is 500391.8\$/day, which is the sum of cost due to power exchange between main power grid and MG (i.e., 71512.6\$/day), cost due to wind power generation (i.e., $295391.3 \$ / \mathrm{hr}$ ), cost due to solar PV power generation (i.e., 91359.7\$/day) and the cost due to BES system and EVs (i.e., 42128.2\$/day). From the simulation results, it can be observed that the TOC obtained in this case is $15.2 \%$ less than Case 1 , and $3 \%$ less than Case 2.

\subsection{Case 4}

In this case, the objective function (i.e., TOC of the system) consists all the terms of (8), (i.e., cost due to power output between main power grid and $\mathrm{MG}$, renewable energy sources (i.e., wind farms and solar PV plants), BES system, EVs and demand response). The TOC obtained in this case is $494157.4 \$ /$ day, which is $16.3 \%$ less than Case 1, $4.2 \%$ less than Case 2, and $1.3 \%$ less than Case 3. 
From the simulation results of four case studies, it can be observed that by operating the MG with RERs, BES system, EV and demand response simultaneously can reduce the total operating cost of the system, which leads to the optimal utilization of hybrid energy sources in the microgrid.

\section{CONCLUSION}

This paper proposes an optimal scheduling approach of Microgrid by optimally utilizing the renewable sources of energy such as wind and solar photovoltaic (PV) powers. The optimal operation of Microgrid is implemented by including the stochastic nature of wind energy generators, solar PV systems, battery storages, electric vehicles and optimal dispatch of schedulable loads, i.e., demand response. In order to reduce the intermittent nature of wind, solar PV powers, electric vehicles (EVs), battery energy storage (BES) systems and demand response are introduced in this paper. Minimization of total operating cost (TOC) (i.e., cost of power exchanged between main power grid and MG, wind, solar PV powers, BES systems, EVs and demand response) of the system is considered as an objective function. In this paper, the probability distribution functions are used to handle the uncertainties related to wind power, solar PV power and load demand. The proposed optimization problem has been solved using the GAMS software. The simulation results of this paper show that the total operating cost of the system has been reduced significantly by optimally utilizing various microgrid components simultaneously.

\section{ACKNOWLEDGEMENTS}

This research work has been carried out based on the support of "Woosong University's Academic Research Funding - 2019”.

\section{REFERENCES}

[1] M. Meiqin, S. Shujuan, L. Chang, "Economic analysis of the microgrid with multi-energy and electric vehicles", 8th International Conference on Power Electronics - ECCE Asia, Jeju, 2011, pp. 2067-2072.

[2] "Renewable Energy Policy Network or the 21st Century", Renewables 2017 Global Status Report, Technical Report. Available. [Online]: http://www.ren21.net/wp-content/uploads/2017/06/ 17-8399_GSR_2017_Full_Report_0621_Opt.pdf

[3] M. Modiri-Delshad, N.A. Rahim, "Optimal operation of microgrid systems", 3rd IET International Conference on Clean Energy and Technology, Kuching, 2014, pp. 1-6.

[4] N. Karthik, A.K. Parvathy, R. Arul, "Optimal Operation of Microgrids-A Survey", International Journal of Applied Power Engineering, vol. 7, no. 2, pp. 179-185, Aug. 2018.

[5] Y. Wang, Y. Huang, Y. Wang, F. Li, Y. Zhang, C. Tian, "Operation Optimization in a Smart Micro-Grid in the Presence of Distributed Generation and Demand Response", Sustainability, vol. 10, pp. 1-25, 2018.

[6] J. Wu, Z. Wu, F. Wu, X. Mao, "A power balancing method of distributed generation and electric vehicle charging for minimizing operation cost of distribution systems with uncertainties", Energy Science and Engineering, vol. 5, no. 3, pp. 167-179, 2017.

[7] F. Farzan, M.A. Jafari, R. Masiello, Y. Lu, "Toward Optimal Day-Ahead Scheduling and Operation Control of Microgrids Under Uncertainty", IEEE Transactions on Smart Grid, vol. 6, no. 2, pp. 499-507, Mar. 2015.

[8] K. Ranjbar, M.M. Ghahderijani, S.M. Barakati, "Effects of Time-Of-Use Demand Response Programs Based on Optimal Operation of a MicroGrid in Market Environment", International Journal of Academic Research in Applied Science, vol. 2, no. 5, pp. 1-12, 2013.

[9] Hussain, V.H. Bui, H.M. Kim, "Impact Analysis of Demand Response Intensity and Energy Storage Size on Operation of Networked Microgrids", Energies, vol. 10, no. 7, pp. 1-19, 2017.

[10] H. Shayeghi, E. Shahryari, "Optimal Operation Management of Grid-connected Microgrid Using Multi-Objective Group Search Optimization Algorithm", Journal of Operation and Automation in Power Engineering, vol. 5, no. 2, pp. 227-239, Dec. 2017.

[11] S. Maghsudlu, S. Mohammadi, "Optimal scheduled unit commitment considering suitable power of electric vehicle and photovoltaic uncertainty", Journal of Renewable and Sustainable Energy, vol. 10, no. 4, 2018.

[12] M. Ghahremani, M.N. Heris, K. Zare, B. Mohammadiivatloo, "Energy Management of Electric Vehicles Parking in a Power Distribution Network Using Robust Optimization Method", Journal of Energy Management and Technology, vol. 2, no. 3, pp. 22-30, 2018.

[13] D. Thomas, O. Deblecker, C.S. Ioakimidis, "Optimal operation of an energy management system for a gridconnected smart building considering photovoltaics' uncertainty and stochastic electric vehicles' driving schedule", Applied Energy, vol. 210, pp. 1188-1206, 2018.

[14] Maulik, D. Das, "Optimal operation of microgrid using four different optimization techniques", Sustainable Energy Technologies and Assessments, vol. 21, pp. 100-120, Jun. 2017.

[15] Gheiratmand, E. Ayoubi, M. Sarlak, "Optimal operation of micro-grid in presence of renewable resources and compressed air energy storage," Conference on Electrical Power Distribution Networks Conference, Semnan, 2017, pp. 131-136. 
[16] W. Liu, D. Wang, X. Yu, H. Jia, W. Wang, X. Yang, Y. Zhi, "Optimal Scheduling of Multi-Source Microgrid Considering Power to Gas Technology and Wind Power Uncertainty", Energy Procedia, vol. 143, pp. 668-673, 2017.

[17] Y. Aiwei, X. Congwei, J. Liwei, "A Joint Scheduling Optimization Model for Wind Power and Energy Storage Systems considering Carbon Emissions Trading and Demand Response", Mathematical Problems in Engineering, vol. 2016, pp. 1-10, 2016.

[18] E. Banguero, H.D.A. Arias, A.J.A. Cardona, D. Hernán, O. Barragánd, "Renewable microgrid operational results and economic evaluation using RETScreenTM", International Journal of Electrical and Computer Engineering (IJECE), vol. 9, no. 2, pp. 723-731, Apr. 2019.

[19] T. Diep-Thanh, Q. Nguyen-Phung, H. Nguyen-Duc, "Stochastic control for optimal power flow in islanded microgrid", International Journal of Electrical and Computer Engineering (IJECE), vol. 9, no. 2, pp. 1045-1057, Apr. 2019.

[20] Md.A. Zaman, Md.H. Rahaman, Md.S. Reza, Md.M. Islam, "Coordinated Control of Interconnected Microgrid and Energy Storage System", International Journal of Electrical and Computer Engineering (IJECE), vol. 8, no. 6, pp. 4781-4789, Dec. 2018.

[21] M.R.B. Khan, J. Pasupuleti, J. Al-Fattah, M. Tahmasebi, "Optimal Grid-Connected PV System for a Campus Microgrid", Indonesian Journal of Electrical Engineering and Computer Science (IJEECS), vol. 12, no. 3, pp. 899-906, Dec. 2018.

[22] M.R.B. Khan, J. Pasupuleti, J. Al-Fattah, M. Tahmasebi, "Energy management system for PV-Battery microgrid based on model predictive control", Indonesian Journal of Electrical Engineering and Computer Science (IJEECS), vol. 15, no. 1, pp. 20-25, Jul. 2019.

[23] M.A.A. Rahman, B. Ismail, K. Naidu, M.K. Rahmat, "Review on population-based metaheuristic search techniques for optimal power flow", Indonesian Journal of Electrical Engineering and Computer Science (IJEECS), vol. 15, no. 1, pp. 373-381, Jul. 2019.

[24] O. Olatunde, H.A. Rahman, "Allocation of distributed generation and capacitor banks in distribution system", Indonesian Journal of Electrical Engineering and Computer Science (IJEECS), vol. 13, no. 2, pp. 437-446, Feb. 2019.

[25] R. Habachi, A. Touil, A. Boulal, A. Charkaoui, A. Echchatbi, "Solving economic dispatch and unit commitment problem in smart grid system using eagle strategy based crow search algorithm", Indonesian Journal of Electrical Engineering and Computer Science (IJEECS), vol. 14, no. 3, pp. 1087-1096, Jun. 2019.

[26] R. Habachi, A. Touil, A. Boulal, A. Charkaoui, A. Echchatbi, "Resolution of economic dispatch problem of the moroccan network using crow search algorithm", Indonesian Journal of Electrical Engineering and Computer Science (IJEECS), vol. 13, no. 1, pp. 347-353, Jan. 2019.

[27] S.S. Reddy, J.Y. Park, C.M. Jung, "Optimal Operation of Microgrid Using Hybrid Differential Evolution and Harmony Search Algorithm", Frontiers in Energy, vol. 10, no. 3, pp. 355-362, Sept. 2016.

[28] M. Meiqin, J. Meihong, D. Wei, L. Chang, "Multi-objective economic dispatch model for a microgrid considering reliability", The 2nd International Symposium on Power Electronics for Distributed Generation Systems, Hefei, 2010, pp. 993-998.

[29] Huang, D. Yue, S. Deng, J. Xie, "Optimal Scheduling of Microgrid with Multiple Distributed Resources Using Interval Optimization", Energies, vol. 10, no. 3, pp. 1-23, 2017.

[30] Arabali, M. Ghofrani, M.E. Amoli, "Cost analysis of a power system using probabilistic optimal power flow with energy storage integration and wind generation", Electrical Power and Energy Systems, vol. 53, pp. 832-841, 2013.

[31] J.G. Vlachogiannis, "Probabilistic Constrained Load Flow Considering Integration of Wind Power Generation and Electric Vehicles", IEEE Transactions on Power Systems, vol. 24, no. 4, pp. 1808-1817, Nov. 2009.

[32] R.A. Osama, A.Y. Abdelaziz, R.A. Swief, M. Ezzat, "Microgrid self adequacy optimization using back tracking search algorithm", IEEE Power \& Energy Society General Meeting, Denver, CO, 2015, pp. 1-5.

[33] J. Wu, Z. Wu, F. Wu, X. Mao, "A power balancing method of distributed generation and electric vehicle charging for minimizing operation cost of distribution systems with uncertainties", Energy Science and Engineering, vol. 5, no. 3, pp. 167-179, 2017.

[34] A.A. Moghaddam, A. Seifi, T. Niknam, "Multi-operation management of a typical micro-grids using Particle Swarm Optimization: A comparative study", Renewable and Sustainable Energy Reviews, vol. 16, pp. 1268-1281, 2012.

[35] J. Chen, X. Yang, L. Zhu, M. Zhang, "Study on Microgrid Multi-objective Economic Operation Optimization", International Journal of Advancements in Computing Technology, vol. 5, no. 8, pp. 1218-1229, Apr. 2013.

[36] P.E. Gill, W. Murray, M.A. Saunders, "Snopt: An sqp algorithm for large-scale constrained optimization", SIAM review, vol. 47, no. 1, pp. 99-131, 2005. 